\title{
DIVERSITY RESEARCH IN AN ENGINEERING TECHNOLOGY Program: Promising Practices For Diversity ReSEARCH INITIATIVES IN POST-SECONDARY EDUCATION
}

\author{
Dr. Jennifer Long ${ }^{1}$, Dr. Kostas Apostolou ${ }^{1}$, Michele Mantock ${ }^{1}$, Yvonne Maidment ${ }^{1}$, and Whitney Ross ${ }^{2}$ \\ ${ }^{1}$ W. Booth School of Engineering Practice \& Technology \\ ${ }^{2}$ Paul R. MacPherson Institute for Teaching, Excellence, and Innovation \\ McMaster University, Hamilton, ON \\ Corresponding Author:longjen@mcmaster.ca
}

\begin{abstract}
While efforts are underway to solve gender disparity in engineering, there tends to be a focus on gender at the expense of other diversity considerations. Few Canadian universities collect data about their racialized student population despite human rights advocates and the government of Ontario endorsing such an approach to uncover inequality and better understand the needs of Canada's growing diverse student population. Of those universities that collect demographic information on their student body, few studies dig deep enough to understand how students' identities affect their learning experience. The proposed study goes further to understand faculty, staff and student experiences around teaching and learning. This study views educational experiences holistically (within and outside the classroom) in order to understand how participants face discrimination or exclusion. In this paper, the authors provide an overview of demographic surveys at Canadian universities and describe McMaster University's recent work in this area. The authors then provide a study overview and our intended next steps. It is the hope that this research, and affiliated workshops, will help faculty and staff better understand the lived experiences of discrimination that our students face, and may help illuminate bias and barriers within our educational offerings that go unnoticed.
\end{abstract}

Keywords: Diversity; diverse teaching and learning experiences; student survey; discrimination; engineering technology program.

\section{INTRODUCTION}

In a recent news article describing how little data Canadian universities collect about their racialized (those who identify as being a part of a visible minority) student population, MacDonald and Ward noted that $82 \%$ of universities did not collect racial demographics on their students [9]. The authors noted that "experts, human rights advocates and recently the government of Ontario have endorsed the collection of race-based data as a means of uncovering inequality and better understanding the needs of racialized groups" [9]. McMaster University is one of the 63 universities (of 76 asked) that does not systematically collect such information.

The Canadian engineering profession, which we identify as stretching from university to workplace, has received a lot of attention for its 'leaky pipeline'. The Ontario Women in Engineering (ONWIE) conducted research on gender disparity in accredited engineering programs across Canadian and found that while there is growth in the absolute number of female undergraduate enrollments over the last 10 years, the proportion of female undergraduate students has stagnated at $19-20 \%$ [13]. Furthermore, female engineering students tend to stick to certain disciplines choosing such areas as biosystems, chemical, environmental, and geological engineering, over historically male-dominated areas like software, computer or mechanical engineering. This research identifies the transition from freshman to sophomore year in university as one of the points at which female students drop out of the engineering pipeline (see also Starovoytova Madara and Cherotich 2016 as a comparative).

While efforts are underway to solve gender disparity in engineering, there tends to be a focus on gender at the expense of other diversity considerations. In a recent news article, Y-Vonne Hutchinson, a diversity specialist, notes that for a long time, the focus of technical industries was to hire women, and among them, to focus on white women [1]. This idea is supported by recent research out of the UK where workforce demographics show that diversity remains a challenge, that white women tend to fare better than minority, ethnic, and disabled people and that redress efforts focus disproportionally on gender imbalance [14].

The focus on gender, while important, provides only a partial understanding of the diversity present in Canadian engineering disciplines and workplaces. Hutchinson notes that initiatives need to be "intersectional and holistic, meaning they account for people that have in the past been excluded" [1]. 
With this research, the authors sought to expand the focus of diversity-related initiatives within McMaster University's Faculty of Engineering and to understand how one's identity factors in teaching and learning efforts. Specifically, our project seeks to answer two questions:

1. What is the demographic makeup of students and faculty in the W. Booth School of Engineering Practice \& Technology (SEPT)?

2. What is the impact of one's identity while teaching and learning within SEPT?

This research falls under the purview of pedagogical research as Lawrie et. al [6] have demonstrated that questions of diversity and inclusion as well as the need for equity in teaching and learning are persistent themes in recent pedagogical literature and discourse. From curriculum design and delivery $[7,8]$ and program and institutional management [4], knowing who our students are and how we can best teach them is critical. Further, understanding lived experiences of discrimination that our students face, may help illuminate bias and barriers within our educational offerings that go unnoticed [2].

The intended outcome of this research is to develop (i) evidence-based workshops for faculty and staff and (ii) workshops for students regarding inclusive teaching and learning environments. The vision and mission statement of SEPT states that we will recognize and work to understand the impact of diversity among students, faculty and staff. In line with other research conducted in this field, members of the faculty and staff have created a committee to conduct research in an effort to better understand the teaching and learning experiences of all stakeholders here at SEPT: that is, the students, faculty and staff. We expect that racialized individuals experience education differently depending on their unique identities and that the educational environment (which can include the classroom and school-related activities both on and off campus) may suit some students, faculty and staff better than others.

This paper provides an overview of our research design and progress to date, our intended educational outputs for the faculty and staff in the next school year. Our goal is to create a set of promising practices to make SEPT a more welcoming environment for all stakeholders involved.

\section{UNDERSTANDING STUDENT DIVERSITY}

In a recent study, an Employment Equity Working Committee at McMaster University's conducted an online survey of faculty, staff, and administrators in order to understand 'who is represented' at McMaster [11]. Although survey administrators were hoping for a $70 \%$ completion rate, their survey generated a completion rate just over $43 \%$. Of those employee groups who the working group could report on (with a sufficient response rate to provide anonymity to respondents), the authors found that:

With respect to the designated groups, there is a positive ratio of $63.8 \%$ internal compared to the external $59.4 \%$ for women - a utilization rate gap of $107 \%$. For Aboriginal Peoples, data shows $1.1 \%$ internal representation, versus $1.7 \%$ external availability, and a utilization rate gap of $66 \%$. Persons with disabilities are represented internally at $3.3 \%$ versus an external $4.2 \%$ representation, with a utilization rate of $79 \%$. Similarly, members of visible minorities comprise $9.8 \%$ of internal employees against $17.5 \%$ external, reflecting a $56 \%$ utilization rate. [11] Above, the percentage of historically under-employed groups [women, Aboriginal Peoples from henceforth called First Nations, Metis and Inuit (FMNI), persons with disabilities, and visible minorities] who were working at McMaster are identified as the 'internal representation'. This percentage is then compared to the number of designated group members in the external labour force, called 'external representation'. This latter data is taken from the 2011 National Household Survey and 2012 Canadian Survey on Disability. As a summary finding, the Employment Equity Working Committee argued that McMaster must increase its efforts "to improve diverse representation among our workforce". In a recent report on Islamophobia at McMaster University, McMaster's Equity and Inclusion Office found that "due to the systemic silencing and lack of public voice of acknowledgement surrounding Islamophobic incidents, reporting is not always considered a viable option" [12]. Further, the report authors found that researching Islamophobia on campus "revealed a need for ongoing work to appropriately address the reality and the impact of Islamophobia on our University campus" [12].

Researchers have shown the importance of dealing with diversity in engineering classrooms not only to ensure retention but to help engineering graduates prepare for their diverse workplace [3]. It is with this understanding and the growing diversity of our student population that our research team sought (i) to better understand our student, faculty and staff population and (ii) to use our findings to develop workshops. These workshops will facilitate an inclusive learning environment in all aspects of teaching from student learning to administration and management tasks and will enhance one's ability to teach to a diverse classroom.

Although some universities gather information on selfidentifying Indigenous students, Mount Saint Vincent University, Queen's University, Dalhousie University and Acadia University go beyond this level of reporting and conduct demographic surveys of their student body. McGill University does not typically collect demographic information however, their Principal Task Force on Student Life and Learning conducted an online survey of students in 2009 with the intention of answering the 
following question: "How can the University administration best foster sensitivity to cultural and personal differences in the delivery of academic and other administrative supports to the students, while respecting its primary academic purposes?"

Students were asked about experiences of discrimination with respect to their language, gender, sexual orientation, country of origin, disability, ethnic and/or cultural background, and religion. Overall, the authors found that while the majority of respondents $(58 \%)$ reported never being discriminated against by fellow students, $3.6 \%$ of respondents reported high levels of discrimination based on at least one of the personal characteristics [10].

Such a study helps faculty, staff and administration understand how individual identity may influence one's overall educational experience. Our proposed study at McMaster University would take this question one step further to ask about experiences of discrimination within and outside the classroom, from a holistic perspective; that is, from the perspective of instructors, staff members, and students who are involved in different aspects of the teaching and learning process. Together, this comprehensive overview will help identify where, if any, exclusive spaces, policies or practices exist.

\section{STUDY DESIGN}

This research topic best suits a mixed methods approach in order to provide the investigators with (i) an overview of SEPT's population diversity and (ii) a nuanced understanding of faculty, staff and students' explanation of their experiences. This study incorporates online surveys of faculty, staff as well as students. All participants must be current McMaster employees or students in SEPT. Questions for faculty and staff are worded slightly different from those sent to students. SEPT has both an undergraduate and graduate program; however, the applied engineering Master's program only runs for one year. Therefore, while the online surveys will be run in both the fall and winter semester for undergraduate students and staff, graduate students will only be asked to take part in the survey in the winter semester. This timing will also hold true for first-year undergraduate students with the reasoning that students are still orienting themselves with the university and building educational experiences.

In addition to the online survey, undergraduate students will be asked to take part in focus groups conducted by a third-party investigator - our collaborating partner at McMaster's teaching and learning institute. The research team hopes that diversifying our data collection methods will provide numerous nuanced perspectives.

\subsection{Development of Survey Questions}

After the letter of information and consent screen, participants taking part in the online survey are asked to read through a list of defined terms that are used in the survey, before answering any questions. The investigators ask survey participants to open up this definitions page in another window to allow for easy reference throughout the survey. The online survey is broken into two sections, beginning with demographic characteristics and ending with personal experiences.

Questions for the demographic section were primarily drawn from two sources: (i) Statistics Canada 2016 Long form census [15]; and (ii) McMaster University SelfIdentification Survey [5]. Examples of these demographic questions include but are not limited to:

- Do you identify as a woman?

- Do you identify as a person who is transgender, gender non-conforming, gender variant, or an analogous term?

- Do you self-identify as a member of a visible minority?

- Do you self-identify as a member of a minority religious group?

Following the section of demographic questions, participants are then asked to answer questions about their personal experiences at SEPT and McMaster. Below is a sample of these questions. Responses are collected using Likert scales and, at times, open text boxes for further explanation:

- In your opinion, how welcoming would you describe the McMaster University campus community in terms of diversity and inclusion?

- In your opinion, how diverse is the staff and faculty working in SEPT?

- In your opinion, how diverse is the student body at SEPT?

- In your opinion, do you think courses taught in SEPT attract diverse students?

- In your experience, how often do you experience discrimination from other SEPT students with respect to your: language, disability, gendered identity, sexual orientation, country of origin, ethnic/cultural background, religion?

- In your experience, how often do you experience discrimination from SEPT faculty and staff with respect to your: language, disability, gendered identity, sexual orientation, country of origin, ethnic/cultural background, religion?

- How prepared do you find SEPT faculty and staff are to respond to incidents of discrimination?

- What resources would you like to have around diversity or discrimination on campus?

- In your experience, how would you describe SEPT's treatment of international students?

Some of these questions were fashioned after questions in McGill's Diversity Study (2009), but the majority were drafted by the corresponding author, Dr. Jennifer Long. Dr. Long has past experience creating surveys on the topic of diversity in Canadian workplaces. Many of the questions 
given in the online survey are reproduced for focus groups with students.

\subsection{Piloting Survey}

In November 2017, McMaster hosted the Conference on Diversity in Engineering on behalf of the Canadian Federation of Engineering Students. There, the research team led a workshop which piloted the online survey questions to a group of 70 undergraduate engineering students. The research team asked the attendees to first take the survey and then provide feedback on the questions. Our goal with this pilot run was to ensure our questions were as inclusive as possible. The authors integrated this feedback into the survey questionnaire and similar changes were made to the faculty and staff online survey where applicable.

\subsection{Survey Distribution and Focus Group Coordination}

The research team is using Lime Survey to facilitate the online survey. There are monetary incentives available to motivate student participation for both the survey and focus group sessions. The online surveys will be deployed at a time convenient to students, faculty and staff, based on their term workload pattern. As mentioned above, the focus groups will be facilitated by a moderator at arms-length from SEPT.

\subsection{Ethical Considerations}

Participants of our online survey or focus groups could be worried that reporting anything that appears to be less than a positive experience would be met with censure. Further, there is a potential risk of participants being identified due to the detailed nature of our questions which may infringe on privacy rights of the participants. These risks may be greater for participants who are at the heart of our research questions (that is, due to the smaller number of students, faculty and staff who identify as a minority in SEPT, their answers may make them more easily identifiable due to their unique identity within the School).

In addition to following the protocols set out by McMaster's recent self-identification survey, the researchers have also obtained ethics clearance from McMaster University. SEPT has a partnership with a local college, Mohawk College, and as such, the researchers also obtained ethics clearance from Mohawk's Research Ethics Board to cover any instances where students might speak of their experiences at either campus. Further, when disseminating our research findings, any data with too few respondents will not be shared unless in aggregate form.

\section{NEXT STEPS}

To date, our research team has not distributed any surveys or hosted any focus groups due to temporary administrative and logistical setbacks. Next steps include collecting and analyzing data over a 12-month period with the help of student researchers. The research team will draft a report of these findings for the Director of SEPT and the Dean of Engineering.

Following this deliverable, the research team will work to integrate these SEPT-specific findings into workshops for various audiences around inclusive teaching and learning. For example, a module on building inclusive classrooms will incorporate case studies of student, faculty and staff experiences. These workshops will be developed with the help of McMaster's teaching and learning centre and the Equity and Inclusion Office on campus.

There has been interest in expanding the scope of this research beyond SEPT which may prove useful when trying to report on demographic groups with a very small population. The research team hopes to make this data collection systematic and run the study every 3 to 5 years.

\section{CONCLUSION}

Building on McMaster's recent demographic survey of employees, this research seeks to better understand how students', faculty and staff's identity influence their educational experiences in teaching and learning. In this paper, the authors provided an overview of demographic surveys at other Canadian universities and described McMaster's past work in this area. The authors then provide an overview of the proposed study's methods and our intended next steps. It is the hope that this research, and affiliated workshops, will help faculty and staff understand the lived experiences of our students and colleagues and identify any unseen bias and barriers within our educational offerings.

\section{Acknowledgements}

The authors wish to acknowledge Grace Couper for putting the surveys online and the workshop attendees at the Conference on Diversity in Engineering for their feedback on our survey.

\section{References}

[1] M. Braga. "Canadian tech companies say they value diversity - but what are they doing about it?" Internet: http://www.cbc.ca/news/technology/canada-techcompanies-diversity-reports-2017-1.4194556, July 13, 2017 [November 8, 2017].

[2] H. Forsyth and A. Cairnduff. "A scholarship of social inclusion in higher education: Why we need it and what it should look like". Higher Education Research \& Development, vol. 34, no. 1, pp. 219-222, 2015.

[3] E. V. Goethe and C. M. Colina. "Taking Advantage of Diversity within the Classroom." Journal of Chemical Education, vol. 95, no. 2, pp 189-192, 2018.

[4] C. Hockings. Inclusive learning and teaching in higher education: a synthesis of research. York: The Higher Education Academy. Available as of May 9, 2018 from 
www.heacademy.ac.uk/assets/York/documents/ourwo rk/inclusion/wp/inclusive teaching and learning in he.doc

[5] Institutional Research and Analysis, McMaster University Employee Self-Identification Report, Hamilton, Canada, 2017, 20 pp. Available as of May 10, 2018 from http://www.workingatmcmaster.ca/med/document/Mc Master-University-Employee-Self-IdentificationReport---April-26-2017-1-51.pdf

[6] G. Lawrie, E. Marquis, E. Fuller, T. Newman, M. Qiu, M. Nomikoudis, F. Roelofs, and L. van Dam, "Moving towards inclusive learning and teaching: A synthesis of recent literature," Teaching \& Learning Inquiry, vol. 5, no. 1, pp. 1-13, 2017. Available as of March 9, 2018 from https://files.eric.ed.gov/fulltext/EJ1148444.pdf

[7] A. Lee, R. D. Williams, M. A. Shaw, and Y. Jie. "Firstyear students' perspectives on intercultural learning". Teaching in Higher Education, vol. 19, no. 5, pp. 543554, 2014.

[8] A. Lombardi, H. Gerdes, and C. Murray. "Validating an assessment of individual actions, postsecondary supports, and social supports of college students with disabilities," Journal of Student Affairs Research and Practice, vol. 48, no. 1, pp. 107-126, 2011.

[9] J. McDonald and L. Ward. "Why so many Canadian universities know so little about their own racial diversity." Internet: http://www.cbc.ca/news/canada/race-canadianuniversities-1.4030537, March 21, 2017 [November 13, 2017].

[10] McGill University. Student Demographic Survey, Final Report, 2009. Montreal, Canada, 2011, 33 pp. Available as of May 9, 2018 from https://www.mcgill.ca/studentlifeandlearning/files/stu dentlifeandlearning/final_report_1.pdf
[11] McMaster University, Employment Equity Report Advancing Workforce Diversity, Equity and Inclusivity at McMaster University, Hamilton, Canada, The Employment Equity Working Committee. 2017, 38 pp. Available as of May 10, 2018 from http://www.workingatmcmaster.ca/med/document/Em ployment-Equity-Report-min-(1)-1-51.pdf

[12] McMaster University Equity and Inclusion Office, Report on the Challenging Islamophobia on Campus Initiative: December 2015 - May 2016, Hamilton, Canada, 2017, 27 pp. Available as of May 10, 2018 from

https://equity.mcmaster.ca/documents/challengingislamophobia-on-campus-initiative-report-20152016.docx

[13] ONWIE. "Resources + Tools $\mid$ Statistics | Percentage of Female Undergraduates in Engineering (Canada)." Internet:http://www.onwie.ca/resourcestools/statistics/percentage-of-female-undergraduatesin-engineering-canada-, 2018. [November 10, 2017].

[14] Royal Academy of Engineering, Diversity and inclusion in engineering survey report 2015 including trends, similarities and differences with the highways and transportation sector. London, UK: Royal Academy of Engineering Diversity Leadership Group, 2015, 44 pp. Available as of May 9, 2018 from https://www.raeng.org.uk/policy/diversity-inengineering/diversity-and-inclusiontoolkit/documents/diversity-and-inclusion-inengineering-survey-repo

[15] Statistics Canada. "2016 Census of Population questions, long form (National Household Survey)." Internet: $\quad$ http://www12.statcan.gc.ca/nhsenm/2016/ref/questionnaires/questions-eng.cfm, December 8, 2015 [November 2, 2017]. 